\title{
ANÁLISE DAS INTERVENÇÕES NAS EXPORTAÇÕES BRASILEIRAS DE CAFÉ SOLÚVEL PARA UNIÃO EUROPEIA NO PERÍODO DE 1995 A 2014
}

\author{
Analysis of Interventions on Brazilian Coffee Exports Soluble to \\ European Union in the Period 1995 to 2014
}

\begin{abstract}
RESUMO
O presente trabalho teve por objetivo analisar o efeito de choques internacionais no mercado de café solúvel sobre a quantidade exportada de café solúvel do Brasil para a União Europeia, do primeiro trimestre de 1995 ao último trimestre de 2014. Como referencial analítico, utilizou-se o modelo de análise de intervenção para modelos ARIMA multivariados. Os resultados indicam que o PIB da União Europeia é significativo para as exportações brasileiras, além disso identificou-se que a Crise de 2008 e a intervenção na OMC DS 154 de 1998 afetaram negativamente o comportamento das exportações conforme esperado. Porém, a intervenção junto a OMC, DS209 de 2000 e a taxa de câmbio para o setor cafeeiro conilon não se comportaram conforme esperado. De maneira geral os resultados demonstraram efetivos para uma boa análise do comportamento das exportações brasileiras de café solúvel para União Europeia no período proposto.
\end{abstract}

Larissa Carla Siqueira

Universidade Federal de Lavras

larissasiqueira90@yahoo.com.br

Caio Peixoto Chain

Universidade Federal de Lavras

caiopeixotochain@gmail.com

Renato Silvério Campos

Universidade Federal de Lavras

renatocampos.ufla@gmail.com

Recebido em: 17/09/2019. Aprovado em: 22/08/2020.

Avaliado pelo sistema double blind review

Avaliador científico: Paulo Henrique Montagnana Vicente Leme

DOI: $10.48142 / 2238-68902019 v 21 n 1-3 p 148160$

\begin{abstract}
This study aimed to analyze the effect of international shocks in the soluble coffee market over the amount exported from Brazil soluble coffee to the European Union, the first quarter of 1995 to the last quarter of 2014. As analytical framework, we used the intervention analysis model for arima multivariate models. The results indicate that EU GDP is significant for Brazilian exports also identified that the 2008 crisis and the intervention of the WTO DS 1541998 negatively affected the export performance as expected. However, the intervention with the WTO, 2000 DS209 and the exchange rate for the coffee sector conilon not behaving as expected. In general, the results showed effective for a good analysis of the behavior of Brazilian exports of soluble coffee to the European Union in the proposed period.
\end{abstract}

Palavras-chave: Modelo ARIMA. Multivariado. Choques Internacionais. Café Solúvel.

Keywords: ARIMA Model. Multivariate. International Shocks. Soluble Coffee.

\section{INTRODUÇÃO}

A importância do café na economia mundial é inquestionável, é um dos mais valiosos produtos primários comercializados no mundo, além disso, seu cultivo, processamento, comercialização, transporte e mercado contribuem para movimentar a economia mundial. Em países em desenvolvimento o cultivo do produto também é fundamental, em alguns casos a exportação de café chega a contribuir com até $70 \%$ das divisas. Esse fato demonstra o quão importante é a atividade cafeeira para a estruturação das economias dos países produtores.

Na economia brasileira a importância da commodity café é consolidada, desde o Ciclo do Café ${ }^{1}$ até os dias atuais, o produto é o responsável por assegurar os bons números

'Durante a República Velha com a queda nas exportações de algodão, açúcar e cacau, os fazendeiros sentiram a grande oportunidade de obterem altos lucros com o "ouro negro", o café. Passaram a investir mais e ampliaram os cafezais. Na segunda metade do século XIX, o café tornouse o principal produto de exportação brasileiro, sendo também fortemente consumido no mercado interno. 
do balanço de pagamentos ${ }^{2}$ do país, além de possibilitar o desenvolvimento e industrialização de várias regiões.

O café torrado e moído vem ganhando status de "speciality" no mercado internacional, em razão das exigências cada vez maiores dos consumidores. Outro mercado relevante do café industrializado está no café solúvel, que corresponde por $21 \%$ do consumo mundial e possui inúmeras vantagens decorrentes de tal processamento, principalmente no que tange ao valor agregado, além do fato de ser gerador de empregos no país (FERREIRA, 2013).

Porém, as firmas brasileiras de café solúvel enfrentam obstáculos internos e externos para o crescimento de suas exportações. No campo interno o regime de drawback $^{3}$ e sua viabilidade (BARBARESO et al., 2017). No campo externo, a União Europeia sobretaxa o café solúvel importado do Brasil em $9 \%$, taxa que não incide sobre outros produtores.

Sendo o Brasil o maior exportador de café solúvel e a União Europeia o maior importador (Ministério do Desenvolvimento, Indústria e Comércio - MDIC, 2015) e diante da importante e peculiar relação de comércio entre Brasil e União Europeia, faz-se necessário investigar os determinantes das exportações brasileiras de café solúvel para a União Europeia. Diante do exposto, a presente pesquisa tem como objetivo verificar o comportamento das exportações brasileiras de café solúvel para a União Europeia, especificamente as intervenções ocorridas ao longo do período de 1995 a 2014.

O trabalho está dividido em uma breve contextualização, relatando a relação comercial entre Brasil e União Europeia, além das considerações sobre a Organização Mundial do Comércio (OMC), seguido pela metodologia, enfatizando os modelos de intervenção ARIMA, em seguida as discussões e resultados e, por fim, as considerações finais, além desta introdução.

\section{CONTEXTUALIZAÇÃO}

A presente seção está fundamentada em conceitos que serão elucidados por orientarem as perspectivas analíticas contidas na seção de resultados e discussões. Portanto, são abordados temas sobre a relação comercial de café solúvel entre Brasil e União Europeia, bem como suas disputas na Organização Mundial do Comércio - OMC.

'É um instrumento da contabilidade nacional referente à descrição das relações comerciais de um país com o resto do mundo.

${ }^{3} \mathrm{O}$ regime de drawback, criado pelo Decreto-Lei $n^{\circ} 37 / 1966$, consiste em desonerar o imposto de importação de bens insumos vinculados a um compromisso de exportação de bens finais com maior valor agregado.

\subsection{Referencial Teórico}

A teoria econômica busca explicar os determinantes do comércio internacional por meio de curvas de oferta de exportações e demanda por importações. A curva de demanda por importações representa o excedente do consumidor do país importador em relação ao que os produtores dos países exportadores capazes de ofertar. A curva de oferta de exportação representa o excedente do produtor do país exportador não consumido internamente.

A principal variável que teoricamente explica a oferta e a demanda é o preço internacional. Se o preço internacional estiver inferior ao preço doméstico do país importador ocorre uma demanda por importação, caso o preço internacional esteja superior ao preço doméstico do país exportar, ocorre uma geração de excedente que forma a oferta de exportação. Essa interação tende a gerar um preço internacional de equilíbrio. Esse modelo é conhecido como equilíbrio parcial (KRUGMAN; OBSTFELD; MELITZ, 2015).

Assim, a variáveis básicas que deslocam as curvas de oferta de exportações são os preços externos e internos, taxa de câmbio, renda mundial e subsídios à exportação, enquanto a curva de demanda por importações é influenciada por preços externos e internos, taxa de câmbio, renda nacional e barreiras à importação (VASCONCELLOS; GARCIA, 2014). Outras variáveis como crises econômicas, eventos climáticos, entre outros, também podem deslocar as curvas de oferta e demanda.

\subsection{O Mercado de Café Solúvel entre Brasil e União Europeia}

De acordo com Bragança (2000) não existem barreiras à entrada do café verde no mercado americano e europeu, pois são os principais destinos das exportações brasileiras e grandes exportadores mundiais de café processado. Em relação ao café torrado, a entrada no mercado internacional exige uma série de pré-requisitos que dificultam a exportação. Para o café solúvel, existem barreiras tarifárias desiguais entre os países concorrentes.

Nishijima e Saes (2008) afirmam que o café solúvel brasileiro sofre fortes barreiras tarifárias na União Europeia. As indústrias dos países concorrentes ou são isentas das taxas de importação, sob alegação de uma política de cooperação ao combate do narcotráfico, ou são taxadas com uma menor alíquota, como no caso do México e Índia. Diante desse contexto Nishijima e Saes (2010) identificam queda no potencial de crescimento das exportações em função das barreiras impostas ao café solúvel brasileiro no período 1995 a 2003. 
Ainda segundo os autores, a discriminação tarifária da União Europeia em relação ao café solúvel brasileiro teve início no ano de 1991, quando começou a vigorar o Sistema Geral de Preferências (SGP) em 1990. O sistema isentava de tarifas as importações de café solúvel originárias dos países Andinos - Bolívia, Colômbia, Equador e Peru - sob a égide do combate ao narcotráfico, caracterizado como Regime de Drogas (RD). Em 1992, o Conselho de Ministro da Comunidade Econômica Europeia (CEE) estendeu tal isenção tarifária aos países da América Central.

Em relação ao café solúvel brasileiro, as plantas das fábricas no país tinham ativos específicos para os clientes europeus, por isso, durante os primeiros anos do regime de drogas, os produtores brasileiros reduziram suas margens de lucros e se mantiveram no mercado.

No ano de 1996, a União Europeia reavaliou o SGP, instituindo um novo mecanismo de graduações tarifárias de acordo com o grau de desenvolvimento econômico dos países. O Brasil foi considerado como desenvolvido e a partir de janeiro de 1997 teve o café solúvel taxado em 10,1\% pela União Europeia. Os países do Pacto Andino continuaram a desfrutar de isenção tarifária. Após a aprovação da política discriminatória em 1990, a Associação Brasileira da Indústria de Café Solúvel (ABICS) iniciou ações para tentar reverter a posição da UE. Para levar o processo adiante era necessário, além da argumentação jurídica, comprovar o dano econômico, estabelecendo o nexo causal entre o regime de drogas e a perda de market share na União Europeia pelo solúvel brasileiro.

Em maio de 2001, depois de várias negociações, inclusive tendo o caso sido levado ao Órgão de Solução de Controvérsias da Organização Mundial do Comércio - OMC (DSB), os europeus estabeleceram um sistema de cotas para o Brasil, no âmbito do Regime de Nação Mais Favorecida (NMF).

\subsection{Considerações sobre a Organização Mundial do Comércio}

O objetivo do sistema Bretton Woods ${ }^{4}$ era regular a política econômica internacional a partir da $2^{\circ}$ Guerra Mundial, era formado por três pilares básicos: Banco Mundial, Fundo Monetário Internacional (FMI) e a Organização Internacional do Comércio, este último não foi efetivamente criado porque o congresso americano não

${ }^{4}$ As conferências de Bretton Woods, definindo o Sistema Bretton Woods de gerenciamento econômico internacional, estabeleceram em julho de 1944 as regras para as relações comerciais e financeiras entre os países mais industrializados do mundo. ratificou o acordo necessário para isso. Foi então criado um acordo provisório, Acordo Geral sobre Tarifas e Comércio (GATT), com objetivo de diminuir as barreiras comerciais e a garantir um acesso mais equitativo aos mercados por parte de seus signatários e não a promoção do livre comércio.

A crise do petróleo nos anos 1970 ocasionou uma grave recessão econômica com crescente nível de desemprego, motivando assim, os governos dos países desenvolvidos a adotarem medidas protecionistas, fato esse que demonstrou a falta de efetividade do GATT. Assim, em 1995, após a Rodada Uruguai, a OMC entrou em funcionamento em substituição ao GATT.

Rêgo (1996) define as principais funções da OMC como: gerenciar os acordos multilaterais e plurilaterais de comércio negociados por seus membros, incluindo bens, serviços e propriedade intelectual; solucionar as divergências comerciais; mediar as negociações sobre temas já cobertos pelas regras multilaterais de comércio e sobre novas questões; supervisionar as políticas comerciais nacionais; cooperar com o Banco Mundial e o FMI na adoção de políticas econômicas em nível mundial.

\subsection{O Sistema de Solução de Controvérsias da OMC}

O Sistema de Solução de Controvérsias da OMC é um mecanismo que pode ser acionado sempre que um membro entender que a ação de outro anula ou reduz os ganhos comerciais de uma negociação previamente firmada (ainda que sem a violação dos tratados) ou desrespeita algum tratado oficial da OMC. Ou seja, ao invés de partir para uma retaliação, o membro que se sentir prejudicado pela prática comercial de seu parceiro pode recorrer ao Órgão de Solução de Controvérsias (OSC) da OMC.

O procedimento que deve ser adotado para resolução multilateral de um contencioso (disputa comercial no âmbito da OMC) pode possuir até quatro etapas com prazos específicos: consulta, painel, apelação e implementação. Em geral, muitos contenciosos são solucionados ainda na etapa de consulta, pois as partes entram em acordo ou entendem que a relação custo/beneficio - tanto politico quanto econômico - não é vantajosa.

Esse processo será apresentado no Quadro 1 conforme Varella (2009):

Após esses prazos, se o membro demandado mantiver sua posição de infração quanto às normas comerciais, o membro demandante pode solicitar uma ação de sanção comercial, ou seja, alguma medida compensatória ou suspensão de concessões comerciais. Operacionalmente, existe uma retaliação comercial normalmente no mesmo 
produto ou setor e se não for possível, em outro setor de comércio. Uma ferramenta utilizada para tal é o incremento de imposto de importação que causa prejuízos ao outro membro. A retaliação pode ser aplicada em até 15 meses e após esse prazo as medidas devem ser revisadas.

\subsection{Disputas Comerciais entre Brasil e União Europeia, no Âmbito da OMC}

Foram levantados dois casos de disputas comerciais (Dispute Settlement-DS) entre Brasil e União Europeia na OMC em relação ao café solúvel no período proposto pela pesquisa. Destaca-se que nas duas disputas encontradas o Brasil aparece como demandante, ou seja, reclamante. Esses casos são:

- DS154: Em dezembro de 1998 o Brasil solicitou consultas no que diz respeito ao tratamento preferencial especial em Sistema de Preferências Generalizado (SGP). O Brasil afirmou que o regime do SGP da comunidade europeia (CE) é aplicável aos produtos originários do Grupo Andino dos países e os países do Mercado Comum Centroamericano, que estão conduzindo programas de luta contra a produção e o tráfico de droga. No caso do café solúvel, este tratamento preferencial especial, constante do Regulamento (CE) no 1256/96, é de acesso livre de impostos para o mercado CE.

- DS209: Em outubro de 2000, o Brasil solicitou consultas às medidas comunitárias aplicadas ao abrigo do Sistema de Preferências Generalizado (SGP) que afetam as importações de café solúvel originário do Brasil. As medidas em questão incluem o chamado mecanismo de "graduação", que progressivamente e seletivamente reduz ou elimina preferências concedidas a produtos específicos e / ou países beneficiários do SPG; e o "regime drogas", que confere um tratamento preferencial especial para os produtos originários dos países andinos e do Mercado Comum da América Central que estão conduzindo uma campanha de combate às drogas. Segundo Moreira e Ornelas (2008) o fracasso de um país demandante perante o Mecanismo de Solução de Controvérsias da OMC pode ocorrer quando os seguintes resultados são observados: retaliação, não violação ou resolução desconhecida. Em contrapartida, um sucesso é obtido quando o resultado gera um acordo, implementação ou acordo parcial. Para a análise de um país demandado, esses conceitos são entendidos de forma simétrica.

\subsection{Modelo Conceitual}

Os benefícios vindos da atividade de exportação podem ser percebidos em questões micro e macroeconômicas. Especificamente no comércio de café solúvel entre Brasil e União Europeia, identifica-se que para o Brasil tal relação é de suma importância no sentido de o mesmo ser um país agroexportador e depender desse comércio para manter os bons números de sua balança comercial ${ }^{5}$. Para a União Europeia esse tipo de comércio é relevante, pois, os países envoltos nesse bloco $^{6}$, são territorialmente pequenos e não possuem terras agricultáveis, portanto, para suprir sua demanda pelo consumo do café solúvel recorre-se a importação do mesmo.

QUADRO 1 - Resumo do processo de Solução de Controvérsias da OMC

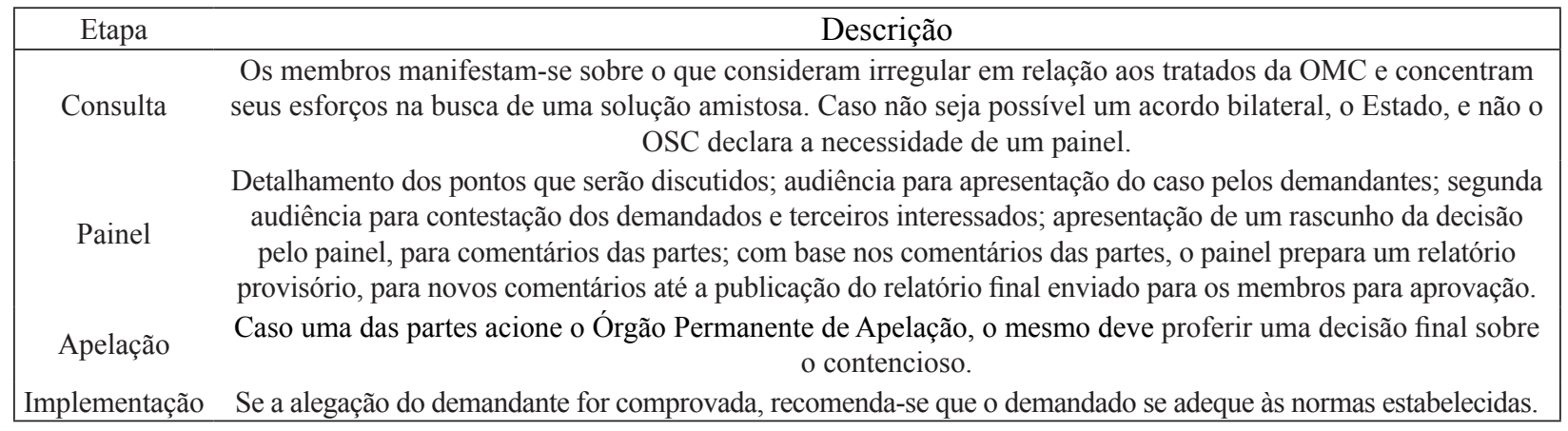

Fonte: Varella (2009)

${ }^{5}$ Em contabilidade nacional, a balança comercial resulta da agregação da balança de bens e de serviços, ambas componentes da balança corrente. A balança comercial registra, portanto, as importações e as exportações de bens e serviços entre os países.

${ }^{6}$ A União Europeia é uma união econômica e política de 28 Estados-membros independentes, Alemanha, Áustria, Bélgica, Bulgária, Chipre, Croácia, Dinamarca, Eslováquia, Espanha, Estónia, Finlândia, França, Grécia, Hungria, Irlanda, Itália, Letônia, Lituânia, Luxemburgo, Malta, Países Baixos, Polônia, Portugal, Reino Unido, República Checa, Romênia, Suécia. 
Segundo Lopes e Vasconcelos (2013) as exportações dependem basicamente da renda, ou seja, o Produto Interno Bruto (PIB), pois, quanto maior o nível de atividade nos países, maior será a demanda internacional, repercutindo positivamente sobre as transações comerciais de tal país, e da taxa de câmbio real, pois, quanto mais desvalorizada for esta última, maior será a competitividade dos produtos internos, aumentando as exportações.

Nesse sentido, ao trabalhar com questões internacionais, faz-se necessário incluir tais variáveis de controle, PIB e taxa de câmbio, para que os resultados sejam os mais fidedignos possíveis. Diante de tal fato, é proposto a primeira hipótese de investigação:

$H 1=$ As variáveis de controle, PIB e taxa de câmbio para o setor de café conilon, influenciam positivamente o comportamento das exportações brasileiras de café solúvel para a União Europeia no periodo de 1995 a 2014;

Além disso, para atingir o objetivo proposto pela pesquisa, o de verificar o comportamento das exportações brasileiras de café solúvel para a União Europeia, especificamente as intervenções ocorridas ao longo do período de 1995 a 2014, serão analisadas duas DS's entre Brasil e União Europeia na $\mathrm{OMC}$ em relação ao café solúvel no período proposto pela pesquisa:
$\mathrm{H}_{2}=$ As intervenções ocorridas ao longo $d a$ série, DS209 e DS154, influenciam negativamente o comportamento das exportações brasileiras de café solúvel para a União Europeia no período de 1995 a 2014;

Por fim, para tentar captar todos os efeitos que uma série de dados pode sofrer, faz-se necessário inserir variáveis exógenas, ou seja, efeitos externos que direta e indiretamente afetam a trajetória da série investigada. $\mathrm{Na}$ presente pesquisa, foi inserida a variável "Crise de 2008 ", pois, os países da União Europeia foram alguns dos que mais sofreram com o efeito da mesma.

$H_{3}=A$ variável exógena, Crise 2008, influencia negativamente o comportamento das exportações brasileiras de café solúvel para a União Europeia no período de 1995 a 2014.

Diante caracterização apresentada e da percepção de questões ao analisar o comportamento das séries propostas pela pesquisa, propõem-se para fundamentar a pesquisa, a Figura 1 que representa o modelo conceitual teórico que sintetiza as hipóteses que se pretende investigar na pesquisa.

Portanto, para analisar a validade de tais hipóteses serão utilizados modelos de séries temporais, modelos da família Box-Jenkins e modelos de intervenção.

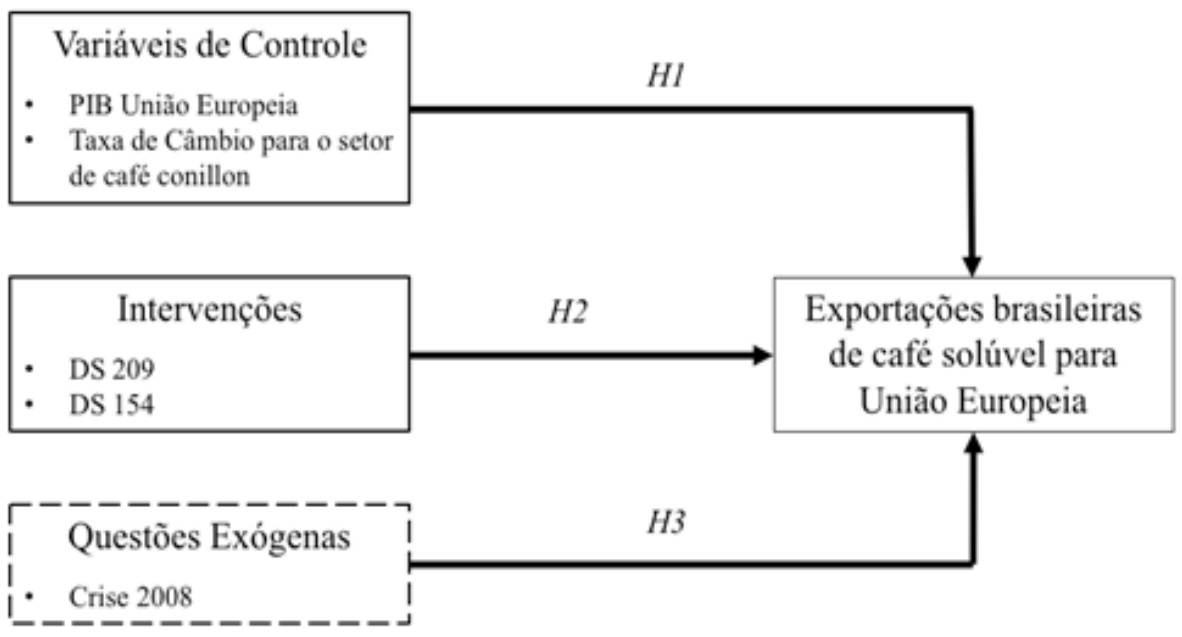

FIGURA 1 - Modelo conceitual

Fonte: Elaboração própria dos autores

${ }^{7} \mathrm{~A}$ crise financeira de 2008 se deu a partir de uma sucessão de falências de instituições financeiras, nos Estados Unidos e na Europa. Instituições estas que participavam de todo complexo sistema financeiro mundial. Essa onda de falência estava relacionada ao que os economistas denominaram de "estouro de uma bolha imobiliária". Sendo assim, é necessário entender o que aconteceu no ramo imobiliário dos EUA para que tal bolha viesse a estourar. 


\section{METODOLOGIA}

\subsection{Séries Temporais}

A análise de série temporal refere-se ao conjunto de observações que possuem uma sequência no tempo. Morettin e Toloi (2006) afirmam que os objetivos de uma análise desse tipo são: investigar o mecanismo gerador da série, realizar previsões de curto prazo, descrever o comportamento da série e por último, verificar a existência de tendência, sazonalidade, ciclo ou algum tipo de periodicidade. Para o presente estudo será utilizado a modelagem da família Box-Jenkins, conhecidos como modelos Autorregressivos Integrados de Médias Móveis (ARIMA) por meio dos modelos multivariados, ou seja, a série temporal é explicada e/ou prevista por seus valores passados e também pelos valores passados de outras variáveis.

As séries históricas trimestrais, de 1995 a 2014, utilizadas na presente pesquisa foram:

- Exportações brasileiras de café solúvel para a Europa (em quilos $-\mathrm{kg}$ ) coletada na base de dados AliceWeb / MDIC;

- PIB da União Europeia, pela ótica da despesa, em US\$ dólares convertidos pela Paridade do Poder de Compra e disponibilizado na base OECD Stats da Organisation for Economic Co-operation and Development (OECD).

- Taxa de câmbio real do café, estimada por: =./

- onde: = taxa de câmbio real; = taxa de câmbio nominal em R \$/US\$, disponível no IPEADATA; $=$ preço do café robusta na bolsa de Nova Iorque, em centavos de US\$ $/ \mathrm{kg}$, coletado no databank / WorldBank; = preço do café solúvel em $\mathrm{R} \$ / \mathrm{kg}$, disponíveis no banco de dados do Instituto de Economia Agrícola de São Paulo.

- Dummies de intervenção para a DS209 a partir de dezembro de 1998 e para a DS154 a partir de outubro de 2000, segundo dados do "Dispute Settlement" da OMC.

- Dummy para a crise econômica mundial entre 2008 e 2009.

\subsection{Modelos da Família Box-Jenkins}

Para Morettin e Toloi (2006), o modelo ARIMA, proposto por Box-Jenkins, pode ser classificado de acordo com os parâmetros $\mathrm{AR}(\mathrm{p})$ (autorregressivos de ordem $\mathrm{p}$ ), MA(q) (média móvel de ordem q) e I(d) (integrado de ordem d) formalizados nas equações (1), (2), (3) e (4).

$$
Y_{t}=\sum_{p=0}^{P} \phi_{P} Y_{t-p}+\varepsilon_{t}
$$

$$
\begin{aligned}
& Y_{t}=\varepsilon_{t}-\sum_{q=0}^{Q} \theta_{q} \varepsilon_{t-q} \\
& Y_{t}=\sum_{p=0}^{P} \phi_{P} Y_{t-p}+\varepsilon_{t}-\sum_{q=0}^{Q} \theta_{q} \varepsilon_{t-q} \\
& W_{t}=\sum_{p=0}^{P} \phi_{P} W_{t-p}+\varepsilon_{t}-\sum_{q=0}^{Q} \theta_{q} \varepsilon_{t-q}, \text { onde } W_{t}=\nabla^{d} Y_{t}
\end{aligned}
$$

Onde:

$\mathrm{t}=1,2, \ldots, \mathrm{T}, \mathrm{p}=1,2, \ldots, \mathrm{P}, \mathrm{q}=1,2, \ldots, \mathrm{Q}, \mathrm{d}=1,2, \ldots$, $\mathrm{D}$ e $\mathrm{k}=1,2, \ldots, \mathrm{K}$

A equação (1) representa uma soma ponderada de "p" observações em um momento anterior t-1 mais um termo aleatório. A segunda equação mostra uma série de somas ponderada de " $\mathrm{q}$ " observações anteriores do ruído. A equação (3) agrega os termos autorregressivos e de média móveis. Por fim, a última equação mostra que sendo estacionária, ou seja, Zt diferenciada, então Wt pode representar um modelo ARIMA(p, d, q) onde "d" é número de diferenças que tornam a série estacionária e é denominado ordem de integração (I).

\subsection{Modelos com Intervenção}

Entende-se intervenção como a ocorrência de algum tipo de evento em um dado instante de tempo T, conhecido a priori. $\mathrm{O}$ efeito da intervenção ao manifestar-se por um intervalo de tempo posterior a mesma, pode afetar temporariamente ou permanentemente a série temporal. Segundo Morettin e Toloi (2006), a análise de intervenção tem por objetivo avaliar o impacto de um ou mais eventos no comportamento de série temporal. Uma classe de modelos levando em consideração múltipla intervenção pode ser formalizada por:

$Z_{t}=\sum_{j=1}^{k} v_{j}(B) X_{j, t}+N_{t}$

Para cada efeito de intervenção, tem-se uma forma apropriada para a função de transferência, v (B), que é dada por: 
$v(B)=\frac{\omega(B) B^{b}}{\delta(B)}$

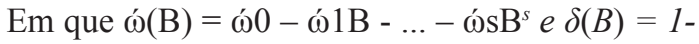
$\delta B-\ldots-\delta r B^{r}$ são polinômios em $\mathrm{B}$ e b é a defasagem no tempo para o início do efeito da intervenção.

\section{DISCUSSÕES E RESULTADOS}

\subsection{Estatística Descritiva}

A Figura 1 apresenta a evolução trimestral das exportações brasileiras de café solúvel para a União Europeia no período entre o primeiro trimestre (jan./fev./mar.) de 1995 ao último trimestre (out./nov./dez.) de 2014. Com a inspeção visual da figura podemos observar três períodos diferentes na série proposta:

$\left.1^{\circ}\right)$ Entre 1995 a 2000 , momento este em que as exportações mantinham volume baixo, pois, o Brasil estava sob fortes barreiras tarifárias impostas pela União Europeia no Sistema Geral de Preferências (SGP).

$2^{\circ}$ ) Entre 2000 e 2008, no qual houve a desvalorização cambial em 1999 e o estreitamento da margem entre os preços dos cafés no mercado interno e externo a partir da safra 2000/01, devido ao crescimento da produção brasileira de robusta, significaram a retomada das exportações brasileiras, além disso, em 2001, o Brasil também conseguiu obter da UE cota livre de taxa, após ter recorrido à Organização Mundial do Comércio (OMC).

$3^{\circ}$ ) Pós o ano de 2008, momento este que marcado pela Crise Econômica Mundial, as exportações brasileiras reduziram significativamente, pois devido à crise as reservas e poder de compra de todo mundo foram reduzidas, o continente europeu foi um dos mais atingidos diretamente.

Destaca-se que a média de exportações no período estudado foi de $3.571 .900 \mathrm{~kg}$ de café solúvel, o menor volume exportado ocorreu no primeiro trimestre do ano de 1995 , aproximadamente $1.653 .100 \mathrm{~kg}$. Foi observado que no quarto trimestre de 2007, ocorreu o maior volume exportado de café solúvel para União Europeia, com aproximadamente $6.139 .700 \mathrm{~kg}$ de café solúvel, período este anterior a Crise de 2008, no qual as exportações estavam com demandas aquecidas e tendência de crescimento.

Por meio dessa análise, reforça-se a necessidade de acrescentar a variável dummy Crise de 2008 para análise do comportamento das exportações brasileiras de café solúvel para União Europeia, pois, a mesma afetou diretamente as exportações e a variável PIB, conforme demonstrado nas Figuras 2 e 3.

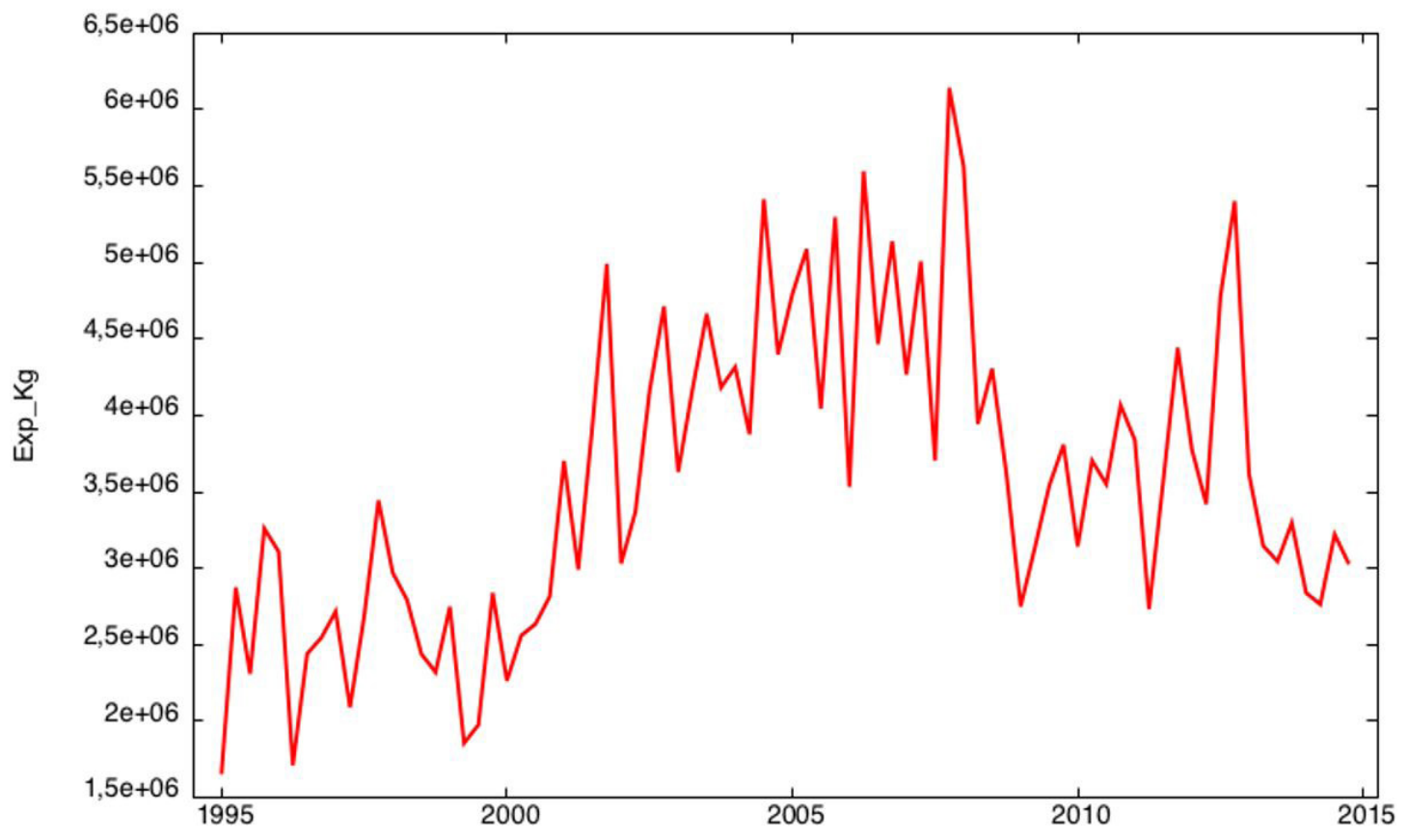

FIGURA 2 - Exportações brasileira de café solúvel para a União Europeia Fonte: Saída do software Gretl

Organizações Rurais \& Agroindustriais, Lavras, v. 21, n. 1-3, p. 148-160, 2019 


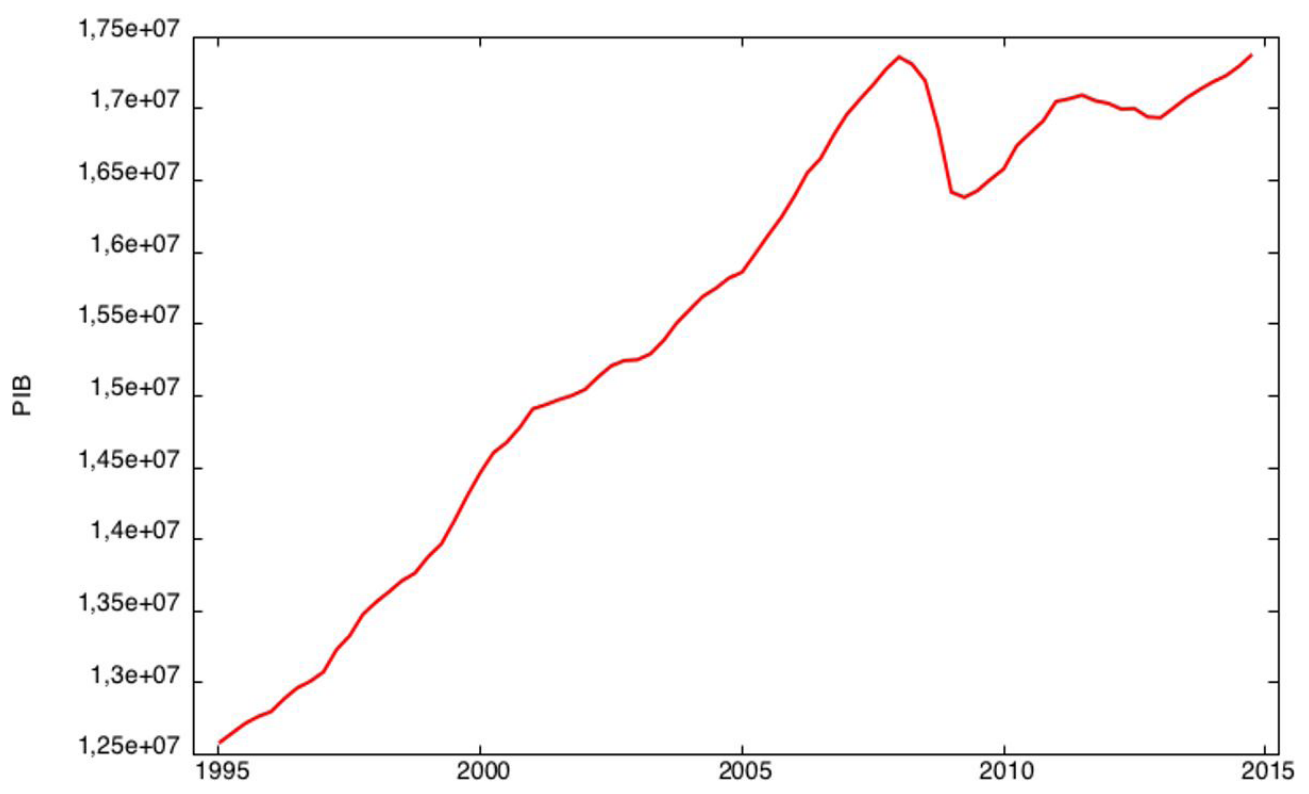

FIGURA 3 - PIB União Europeia

Fonte: Fonte: Saída do software Gretl

A Figura 3 apresenta a evolução da renda, ou seja, do Produto Interno Bruto - PIB da União Europeia no período entre o primeiro trimestre (jan./fev./mar.) de 1995 ao último trimestre (out./nov./dez.) de 2014. Pela observação da série, é evidente o crescimento da riqueza da União Europeia no período proposto. Por meio desse crescimento, confirma-se a força do bloco, que atualmente é composto por 28 países independentes e possui sua moeda própria, o euro. Destaca-se somente a ruptura na tendência de crescimento no ano de 2008, devido a Crise Econômica Mundial daquele ano.

Além disso, identifica-se que a riqueza média da União Europeia no período estudado foi de aproximadamente US\$ 15.547.000,00. O maior PIB ocorreu no quarto trimestre do ano de 2014, com o valor aproximado de US\$17.377.000,00 esse valor demonstra que os países do bloco econômico estudados estão se recuperando da Crise Econômica de 2008. A menor riqueza ocorreu no primeiro trimestre do ano de 1995, período esse em que as economias de todo o mundo estavam sendo modificadas e a União Europeia estava se consolidando.

A Figura 4 apresenta a taxa de câmbio para o setor de café conilon, por meio de tal variável é possível identificar como condições especificas da commodity café afetam ou não diretamente a evolução dessa taxa de câmbio. Ressalta-se que se optou por trabalhar com espécie de café, conilon, pois a mesma é a matéria-prima para a indústria de café solúvel, dessa maneira os resultados encontrados na pesquisa são mais fidedignos ao se referir como a taxa de câmbio influencia o comportamento da exportação brasileira de café solúvel para a União Europeia.

A taxa de câmbio é a referência em valor da moeda nacional com relação à moeda estrangeira. Como exemplo, no Brasil a taxa de câmbio representa o preço, em moeda nacional, de uma unidade de moeda estrangeira, normalmente o dólar.

Pela análise visual da figura pode-se perceber que o comportamento da taxa de câmbio para o setor de café conilon apresentou bastante oscilação, tal oscilação é explicada principalmente pelo período de safra e oscilações de demanda no mercado internacional. Ressalta-se que a menor relação de troca ocorreu no primeiro trimestre de 2001 e a maior no segundo semestre de 2005, conforme pode-se observar no Figura 4.

Ao trabalhar com taxa de câmbio devem-se considerar os conceitos de taxa de câmbio nominal, que é a relação entre quantidades de moeda, e o conceito de taxa de câmbio real, que corresponde ao relativo de preços entre o produto nacional e o estrangeiro. Isso ocorre porque os países têm reflexos do valor da moeda no preço das mercadorias. Ou seja, existe inflação. Portanto, é exatamente para neutralizar o efeito da inflação na definição da taxa de câmbio que se trata a referência dos preços de uma mesma mercadoria em dois países. 


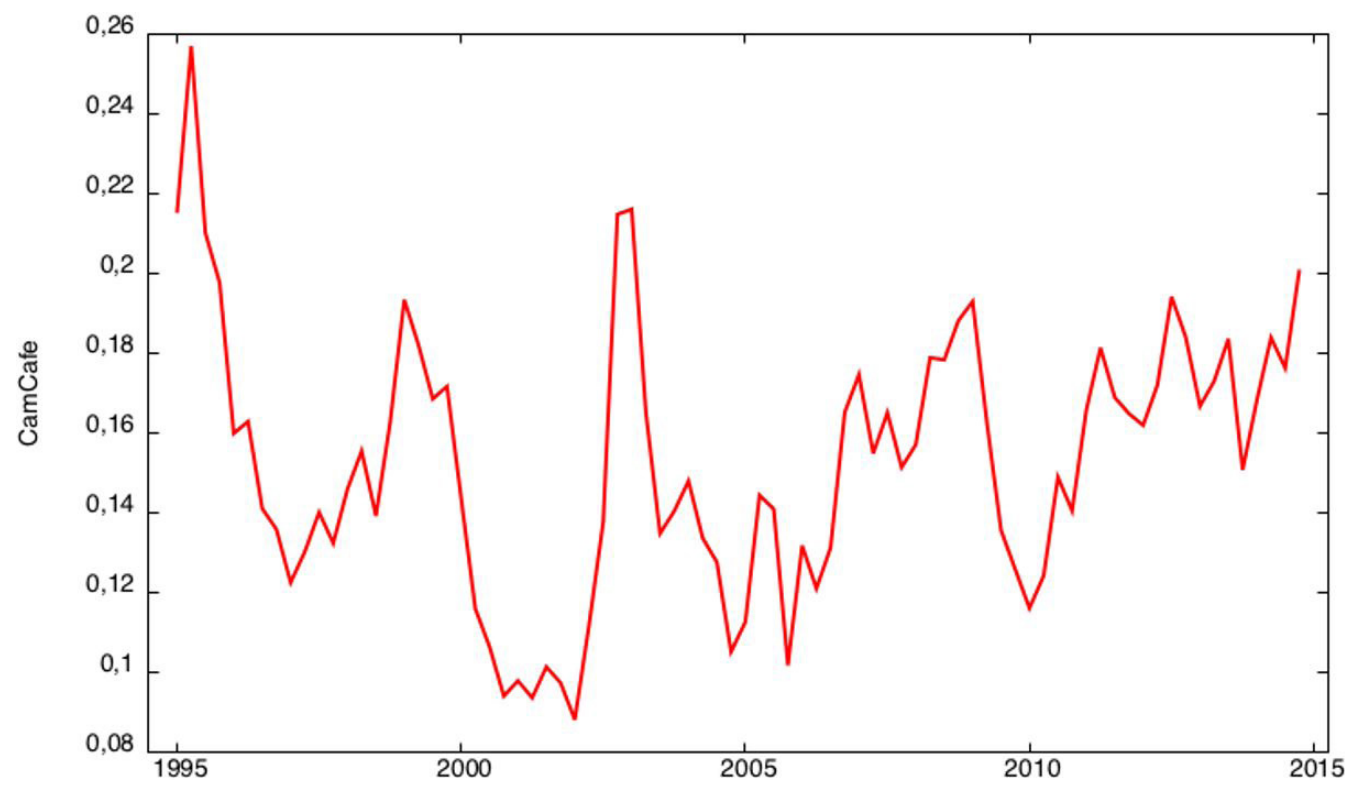

FIGURA 4 - Taxa de câmbio para o setor de café conilon Fonte: Saída do software Gretl

\subsection{Análise Estatística}

Primeiramente, após a análise visual foi realizado o teste de "amplitude X média", para identificar a necessidade de logaritimizar a série. Foi identificado que em todas as séries propostas pela pesquisa a amplitude é diretamente proporcional a média, indicando a necessidade de uma transformação logarítmica para estabilizar a variância. Além disso, destaca-se que nas séries PIB e taxa de câmbio do setor cafeeiro conilon trabalha-se com valores monetários, portanto, logaritimizar a série facilita e melhora as conclusões, tornando-as mais fidedignas aos objetivos propostos.

Em seguida, foi possível detectar por meio da Função de Auto Correlação (FAC) indícios de séries com tendência, e em particular sazonalidade na série taxa de câmbio do setor café conilon, ou seja, apresentavam decaimento gradual para zero, o que caracteriza séries com tendência.

Além disso, a presença da tendência pode ser confirmada por meio da comparação entre a estatística calculada pelo teste de Raiz Unitária Dickey-Fuller Aumentado, conforme Tabela 1 abaixo"

De acordo com os dados da tabela, pode-se concluir que, com exceção da série de taxa de câmbio do setor de café, as demais séries apresentaram raiz unitária e não são estacionárias, portanto, faz-se necessário diferencia-las para que se tornem estacionárias.
TABELA 1 - Teste de Raiz Unitária

\begin{tabular}{cc}
\hline & P - Valor \\
\hline Exportação & 0,4714 \\
PIB & 0,4442 \\
Taxa de câmbio do setor de café conilon & 0,0003 \\
\hline
\end{tabular}

Fonte: Elaborado a partir de dados da saída do software Gretl.

Após a diferenciação das séries, foi gerado o Figura 5 que mostra a FAC e da Função de Auto Correlação Parcial (FACP) da série de exportações brasileiras de café solúvel para a União Europeia, a variável dependente. Essa figura sugere inicialmente o modelo: MA (2) já que a FACP apresenta dois lags fora do Intervalo de Confiança e um AR (1), pois a FAC possui um lag fora do Intervalo de Confiança (IC). Dessa maneira, foram estimados modelos para verificar qual deles se ajusta melhor aos dados.

$O$ resultado do modelo estimado pode ser verificado na Tabela 2. O desempenho dos modelos foi medido de acordo com o Critério de Akaike e de Schwatz, que quando minimizados, podem ser considerados de melhor desempenho. Portanto, infere-se que após os testes necessários o melhor modelo identificado foi $\operatorname{ARIMA}(1,1$, [2]), ou seja, série diferenciada de ordem 1 , autorregressivo de ordem 1, e médias móveis de ordem 2, com defasagem específica do lag 2. 
ACF para d_I_Exp_Kg

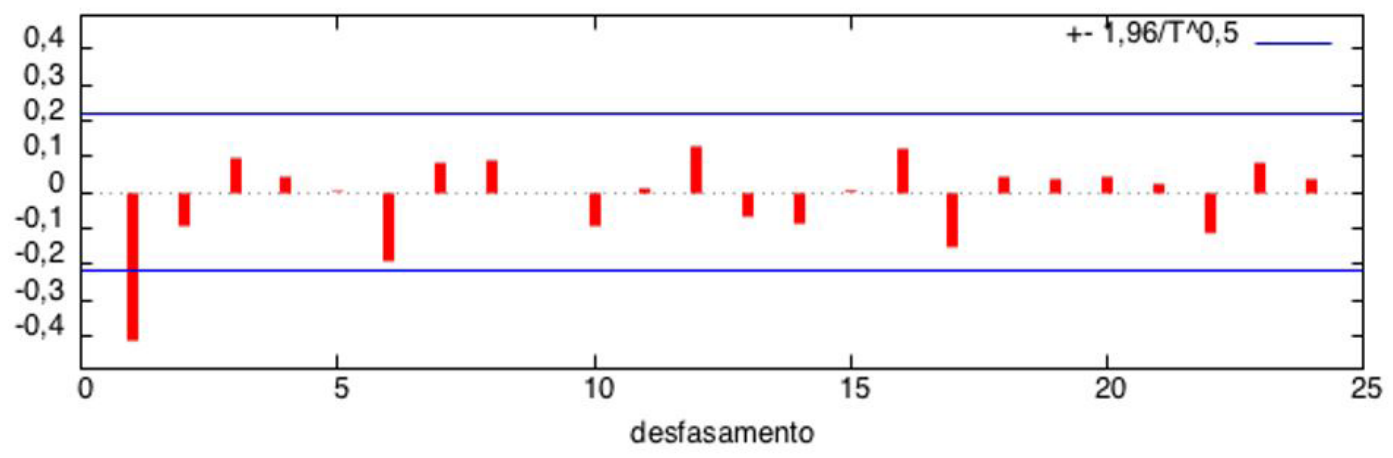

PACF para d_I_Exp_Kg

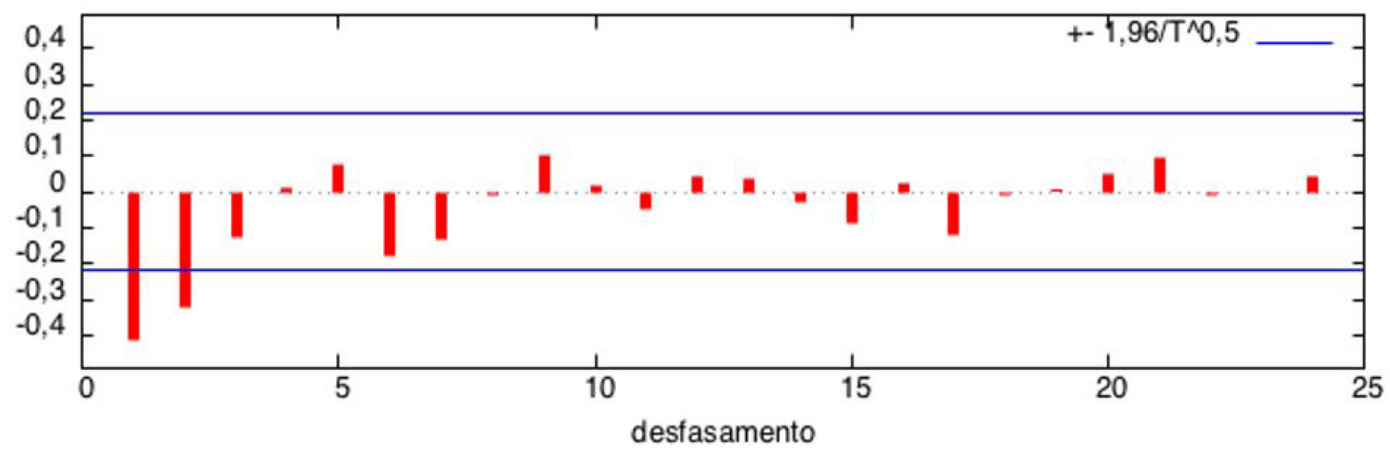

FIGURA 5 - Função de Autocorrelação e Autocorrelação Parcial da Série Diferenciada de exportações brasileiras de café solúvel para a União Europeia

Fonte: Saída do software Gretl

TABELA 2 - Parâmetros e critérios de seleção dos modelos ARIMA.

\begin{tabular}{ccccc}
\hline & Coeficiente & Z & P-Valor & \\
\hline Constante & $-0,0095$ & $-2,190$ & 0,0286 & $* *$ \\
Phi 1 & $-0,9846$ & $-22,410$ & $3,07 \mathrm{e}-111$ & $* * *$ \\
Theta 2 & $-1,0000$ & $-7,313$ & $2,62 \mathrm{e}-13$ & $* * *$ \\
d_1_PIB & 3,7721 & 4,016 & $5,91 \mathrm{e}-05$ & $* * *$ \\
d__CamCafé & 0,0335 & 0,341 & 0,7326 & $* * *$ \\
d_DS2000 & 0,3663 & 3,886 & 0,0001 & $* * *$ \\
d_DS1998 & $-0,2724$ & $-3,031$ & 0,0024 & $*$ \\
d_Crise2008 & $-0,1766$ & $-1,900$ & 0,0575 & $*$ \\
\hline
\end{tabular}

Fonte: Saída do software Gretl

Por meio do resultado do modelo multivariado apresentado na Tabela 2, primeiramente, pode-se inferir de acordo com o teste Q de Box \& Pierce, utilizado para verificar a existência de correlação entre os resíduos, o modelo pode ser considerado como ruído branco, pois, apresentam o valor crítico maior do que a estatística.

A variável PIB da União Europeia confirmou-se significativa ao nível de $1 \%$, seu parâmetro indica que se 
a variável aumentasse em $1 \%$, as exportações brasileiras de café solúvel aumentariam aproximadamente de 3,78\%. Portanto, foi possível identificar que o comportamento das exportações brasileiras de café solúvel no longo prazo é fundamentalmente impulsionado pelo crescimento da renda da União Europeia, ou seja, pelo PIB Europeu. A relevância da renda como determinante do comércio internacional é um consenso já verificado em diversos trabalhos empíricos, especialmente no agronegócio, como Favro, Caldarelli e Camara (2015), Valente, Gomes e Campos (2009), entre outros.

Porém, contrariando a teoria de exportações, a variável taxa de câmbio do setor de café conilon não se confirmou significativa. Tal fato pode ser explicado pela teoria da paridade do poder de compra (PPC) ${ }^{8}$, ou seja, a PPC estabelece que as taxas de câmbio entre duas moedas quaisquer irão se ajustar para refletir mudanças nos níveis de preços entre dois países. Deve-se ressaltar também que a economia brasileira passou por diferentes regimes cambiais durante o período analisado na presente pesquisa.

$\mathrm{O}$ aspecto cambial pode estar associado também ao fato de que grande parte dos setores exportadores brasileiros são tomadores de preços no mercado internacional (KANNEBLEY JUNIOR, 2002) como é o caso do café conilon que possui seu preço cotado na bolsa de Nova Iorque. É interessante destacar que Miranda e Barros (2009) encontraram significância estatística na influência do câmbio real sobre as exportações brasileiras de carne bovina destinada a União Europeia um período de defasagem.

Ao analisar o comportamento da série de exportações brasileiras de café solúvel para União Europeia, identificou-se a necessidade de acrescentar a variável "Crise 2008", pois, este período impactou significativamente tanto na redução da renda dos países europeus quanto no volume de café solúvel importado. Conforme esperado, o resultado demonstrou significativo ao nível de significância de $10 \%$, o que demonstra que a variável Crise 2008 reduziu aproximadamente $0,18 \%$ das exportações brasileiras de café solúvel.

Os efeitos da crise financeira mundial de 2008/2009 sobre as exportações são controversos, dependendo do produto e do mercado. Ferreira et al (2011) verificaram que a crise reduziu significativamente a quantidade exportada de carne suína do Brasil para Hong Kong, porém não impactou o mercado russo. Já as exportações de açúcar bruto do Brasil

${ }^{8} \mathrm{~A}$ teoria da paridade do pode de compra procura medir o quanto uma determinada moeda pode comprar em termos internacionais (normalmente dólar), já que bens e serviços têm diferentes preços de um país para outro. para a Rússia foram negativamente impactadas por essa crise internacional (SOUSA et al. 2011). Por sua vez, Chain et al (2016) demostraram que a comércio agregado bilateral entre Brasil e Argentina foi negativamente impactado pela crise financeira de 2008/2009.

A intervenção na OMC ocorrida em dezembro de 1998, DS 154, comportou-se conforme esperado, ou seja, diante de uma queixa do Brasil contra a União Europeia frente a $\mathrm{OMC}$, as exportações de café solúvel sofreram uma redução, ou seja, ao nível de significância de $1 \%$, ou seja, a intervenção ocorrida na OMC reduziu as exportações brasileiras de café solúvel em aproximadamente em 0,27\%. Resultado semelhante foi encontrado em uma análise agregada para o comércio entre Brasil e Argentina na qual Chain et al. (2016) verificaram que dentre as intervenções causadas por medidas protecionistas de direito internacional reclamadas na OMC, somente a DS355 (resinas PET) apresentou impacto significativo e com sinal esperado no aumento da distância comercial bilateral.

De maneira contrária, a intervenção ocorrida em outubro de 2000, DS 209, não se comportou conforme esperado, no resultado obtido diante de uma queixa do Brasil para União Europeia frente a OMC, as exportações de café solúvel sofreram um aumento, ou seja, ao nível de significância de 1\%, a intervenção ocorrida na OMC aumentou as exportações brasileiras de café solúvel em aproximadamente $0,37 \%$. Tal fato deve-se principalmente ao fato de que no início dos anos 2000 o consumo de café solúvel em todo o mundo aumentou significativamente. Além disso, no ano de 1999 houve a desvalorização cambial e o estreitamento da margem entre os preços dos cafés no mercado interno e externo a partir da safra 2000/01, devido ao crescimento da produção brasileira de robusta, significaram a retomada das exportações brasileiras. Já em 2001, o Brasil também conseguiu obter da UE cota livre de taxa, após ter recorrido à Organização Mundial do Comércio (OMC). Devido a essas questões, a intervenção DS 209 não teve impacto o suficiente para modificar a tendência de crescimento das exportações brasileiras de café solúvel para a União Europeia.

\section{CONSIDERAÇÕES FINAIS}

Conduziu-se esse estudo com o objetivo de verificar o comportamento das exportações brasileiras de café solúvel para a União Europeia, especificamente as intervenções ocorridas ao longo do período de 1995 a 2014, com base nos resultados obtidos por meio dos modelos ARIMA de análise de intervenção. 
Pode-se verificar que a Crise de 2008 e a intervenção na OMC DS 154 de 1998 afetaram negativamente o comportamento das exportações de café solúvel para a União Europeia no período trabalhado conforme esperado pelas hipóteses propostas. A intervenção DS209 de 2000 também se mostrou significativa, porém não conforme esperado, apresentando tendência positiva, resultado esse devido ao aumento do consumo mundial de café solúvel que estabilizou qualquer tendência de queda em relação a intervenção.

Acredita-se que o trabalho tenha contribuído no sentindo de identificar as variáveis que modificaram o comportamento das exportações brasileiras de café solúvel para União Europeia, bem como identificar e sugerir soluções para as disputas comerciais, no sentido de demonstrar que divergências prejudicam o comércio entre os envolvidos, além do consumo dos países importadores.

Além disso, acredita-se que o cálculo da taxa de câmbio própria para o setor de café conilon foi um diferencial para a pesquisa, pois, demonstrou como mudanças específicas na cultura, como sazonalidade, secas, excesso de demanda ou escassez de oferta afetam ou não diretamente as exportações brasileiras de café solúvel para União Europeia. Ressalta-se que no presente trabalho tal variável não se confirmou significativa, porém sugere-se o uso da mesma em pesquisas futuras.

Como limitação do trabalho, ressalta a dificuldade de obtenção de uma série maior de dados, a dificuldade em se obter dados mensais, o que proporcionaria caráter mais fidedigno à presente pesquisa e possibilitaria analisar outras intervenções ocorridas na série, como crise, barreiras tarifárias, problemas na safra, entre outras. Ressalta-se que não foram encontrados na literatura trabalhos com tal metodologia e análise para que se possa realizar uma melhor e maior discussão dos resultados.

Como sugestão para trabalhos futuros aumentar o tamanho da série seja por um período maior de anos ou ainda trabalhar com dados mensais, inserir a variável "consumo mundial de café solúvel", e trabalhar com essa relação comercial para outros países e/ou blocos econômicos, e até mesmo a comparação dos resultados dessa pesquisa com outros países e/ou blocos econômicos.

\section{REFERÊNCIAS}

BARBARESO, J. O. et al. Drawback como solução para melhoria da competitividade da indústria de café solúvel: um estudo de viabilidade. Custos e Agronegócio Online, Recife, v. 13, p. 363- 388, abr. 2017.
BRAGAnÇA, G. G. F. Poder de mercado do café brasileiro nos EUA: abordagem via demanda residual. 2003. 40f. Dissertação (Mestrado em Economia) - FGV Fundação Getúlio Vargas, Rio de Janeiro, RJ, 2003.

CHAIN, C. P. et al. Intervenções na distância econômica entre Brasil e Argentina a partir da constituição do Mercosul. Perspectiva Econômica, São Leopoldo, v. 12, n. 2, p. 17-34, 2016.

FAVRO, J.; CALDARELli, C. E.; CAMARA, M. R. G. Modelo de análise da oferta de exportação de milho brasileira: 2001 a 2012. Revista de Economia e Sociologia Rural, Brasília, v. 53, n. 3, p. 455-476, 2015.

FERREIRA, C. Indústria de café solúvel amarga mais um ano de fraqueza. Valor Econômico, São Paulo, 18 jan. 2013. Disponível em: http://www.valor.com.br/ empresas/2974914/industria-de-cafe-soluvel-amargamais-um-ano-de-fraqueza. Acesso em: 11 dez. 2014.

FERREIRA, M. D. P. et al. Impactos da crise financeira internacional e da influenza A sobre as exportações brasileiras de carne suína. Revista de Economia e Agronegócio, Viçosa, v. 9, n. 1, 2011.

KANNEBLEY JÚNIOR, S. Desempenho exportador brasileiro recente e taxa de câmbio real: uma análise setorial. Revista Brasileira de Economia, Rio de Janeiro, v. 56, n. 3, p. 429-456, 2002.

KRUGMAN, P.; OBSTFELD, M. Economia Internacional: teoria e política, 6 . ed. São Paulo: Pearson, 2005. $558 \mathrm{p}$.

MIRANDA, S. H. G.; BARROS, G. S. C. The application of intervention models to non-tariff trade barriers: a case study of Brazilian beef exports. Journal of International Agricultural Trade and Development, St. Paul, v. 5, n. $2,2009$.

MOREIRA, D. S. B.; ORNELAS, E. O Desempenho do Brasil no Mecanismo de Resolução de Disputas da OMC. Revista EconomiA, Brasília, v. 9, n. 2, p. 265284, 2008.

MORETTIN, P. A.; TOLOI, C. M. Análise de Séries

Temporais. 2. ed. São Paulo: Edgar Blücher, 2006. 
NISHIJIMA, M.; SAES, M. S. M. Análise econômica das barreiras tarifárias ao café solúvel brasileiro. En: XLIV Congresso da SOBER. Fortaleza, 23-26 julho de 2006, Universidade de Fortaleza - UNIFOR. ISBN 8598571016

NISHIJIMA, M.; SAES, M. S. M. Tariff discrimination on Brazil's soluble coffee: an economic analysis. Brazilian Journal of Political Economy, São Paulo, v. 30, n. 2, p. 293-309, 2010.

RÊGO, E. C. L. Do GATT à OMC - o que mudou, como funciona e para onde caminha o Sistema Multilateral de Comércio. Revista do BNDES, Rio de Janeiro, v. 3, n. 6, p. 3-33, 1996.

SOUSA, L. O. et al. Análise das intervenções nas exportações de açúcar bruto do Brasil para a Rússia, de
1997 a 2010. Revista de Política Agrícola, Brasília, v. 20, n. 3, p. 63-76, 2011.

VALENTE, L. C. M.; GOMES, M. F. M.; CAMPOS, A. C. Impactos da influenza aviária no mercado internacional de carnes. Revista de Economia e Agronegócio, Viçosa, v. 7, n.3, 2009.

VARELLA, M. D. Efetividade do Órgão de Solução de Controvérsias da Organização Mundial do Comércio: uma análise sobre os seus doze primeiros anos de existência e das propostas para seu aperfeiçoamento. Revista Brasileira de Política Internacional, Brasília, v. 52, n. 2, p. 5-21, 2009.

VASCONCELLOS, M.A. S.; GARCIA, M.E. Fundamentos de economia. São Paulo: Saraiva, v. 2, 2014. 